\title{
A Simplified Preparation for Relating Cellular Events to Behavior: Mechanisms Contributing to Habituation, Dishabituation, and Sensitization of the Aplysia Gill-Withdrawal Reflex
}

\author{
Tracey E. Cohen, ${ }^{1}$ Saul W. Kaplan, ${ }^{1}$ Eric R. Kandel, ${ }^{1,2,3}$ and Robert D. Hawkins ${ }^{1,2}$ \\ ${ }^{1}$ Center for Neurobiology and Behavior, College of Physicians and Surgeons of Columbia University, ${ }^{2}$ New York State \\ Psychiatric Institute, and ${ }^{3}$ Howard Hughes Medical Institute, New York, New York 10032
}

To relate cellular events to behavior in a more rigorous fashion, we have developed a simplified preparation for studying the gill-withdrawal reflex of Aplysia, in which it is relatively easy to record the activity of individual neurons during simple forms of learning. Approximately $84 \%$ of the reflex in this preparation is mediated through the single motor neuron LDG1, so that changes in the firing of LDG1 can account for most of the changes in behavior. We have used this preparation to investigate cellular mechanisms contributing to habituation, dishabituation, and sensitization by recording evoked firing, the complex postsynaptic potential (PSP), and the monosynaptic component of the complex PSP in LDG1. Our results suggest that habituation is largely attributable to depression at sensory neuron synapses. By contrast, dishabituation and sensitization involve several mechanisms at different loci, including facilita- tion at sensory neuron synapses, enhancement in the periphery (perhaps attributable to post-tetanic potentiation at the neuromuscular junction), and both facilitation and inhibition of excitatory and inhibitory interneurons. Moreover, these different mechanisms contribute preferentially at different times after training, so that information processing in the neuronal circuit for the reflex is distributed not only in space but also in time. Nonetheless, our results also suggest that the neuronal circuit is not a highly distributed neural network. Rather, plasticity of the reflex can evidently be accounted for by several specific mechanisms and loci of plasticity in a defined neural circuit, including a limited number of neurons, some of which make a large contribution to the behavior.

Key words: Aplysia; gill-withdrawal reflex; motor neuron; habituation; dishabituation; sensitization; learning
Previous studies of the Aplysia gill- and siphon-withdrawal reflex have demonstrated a number of parallels between synaptic plasticity in the circuit for the reflex and several simple forms of learning (Castellucci et al., 1970, 1978; Hawkins et al., 1983; Frost et al., 1985; Mackey et al., 1987). Many of the cellular studies of short-term learning, however, involved neuronal analogs in the isolated nervous system, which allowed an analysis of neuronal changes during acquisition but did not provide a direct correlation of those changes with behavior. Neuronal correlates of learning have been observed in ganglia removed from animals after longterm behavioral training and testing (Castellucci et al., 1978; Bailey and Chen, 1983; Frost et al., 1985), but this approach did not permit analysis of neuronal changes during acquisition. To study more fully the relationship between cellular events and learning, we have developed a simplified preparation with which it is relatively easy to record the activity of single identified neurons during behavior. An advantage of this preparation over other, similar preparations (Jacklet and Rine, 1977; Lukowiak, 1977; Byrne et al., 1978b; Wright et al., 1991) is that most of the reflex is mediated through a single motor neuron, so that changes in the firing of that neuron can account for most of the changes in behavior. Despite this simplification, the preparation undergoes

Received Sept. 20, 1996; revised Jan. 2, 1997; accepted Jan. 31, 1997.

This work was supported by grants from the National Institute of Mental Health (MH26212) and the Howard Hughes Medical Institute. We thank J. Koester and I. Kupfermann for their comments, A. Krawetz, H. Ayers, and I. Trumpet for typing this manuscript, and C. Lam and S. Mack for preparing the figures.

Correspondence should be addressed to Dr. Robert D. Hawkins, Center for Neurobiology and Behavior, Columbia University, 722 West 168th Street, New York, NY 10032.

Copyright (C) 1997 Society for Neuroscience $\quad 0270-6474 / 97 / 172886-14 \$ 05.00 / 0$ most of the simple forms of learning shown by the intact animal, including habituation, dishabituation, and sensitization (Hawkins et al., 1990), as well as classical, differential, and second-order conditioning (Hawkins et al., 1993). Moreover, the properties of these forms of learning are not dramatically different from those in the intact animal.

We have begun to use this preparation to perform a systematic "top down" analysis of these simple forms of learning and have assessed the contribution of previously described sites and mechanisms of neuronal plasticity as well as the possible contribution of additional sites and mechanisms. We have started with nonassociative forms of learning (habituation, dishabituation, and sensitization) because (1) previous results from our laboratory and other laboratories suggest that dishabituation and sensitization involve multiple mechanisms, so that the relative contribution of each is uncertain (Mackey et al., 1987; Frost et al., 1988; Marcus et al., 1988; Trudeau and Castellucci, 1993), and (2) we expect that the mechanisms of nonassociative learning in this reflex may be related to the mechanisms of associative learning (Hawkins et al., 1983; Hawkins and Kandel, 1984).

Some of these results have been published previously in abstract form (Hawkins et al., 1992; Kaplan et al., 1993).

\section{MATERIALS AND METHODS}

Adult Aplysia californica weighing 75-120 gm were obtained from the Howard Hughes Mariculture Facility (Miami, FL). They were housed in individual containers in a large aquarium with circulating artificial seawater (Instant Ocean, Aquarium Systems, Mentor, $\mathrm{OH}$ ) at $15^{\circ} \mathrm{C}$ on a 12 $\mathrm{hr}$ light/dark cycle and food-deprived for several days before an experiment was begun. The animals were anesthetized by injection of $50 \mathrm{ml}$ of isotonic $\mathrm{MgCl}_{2}$, and the siphon, gill, mantle, and abdominal ganglion 
A

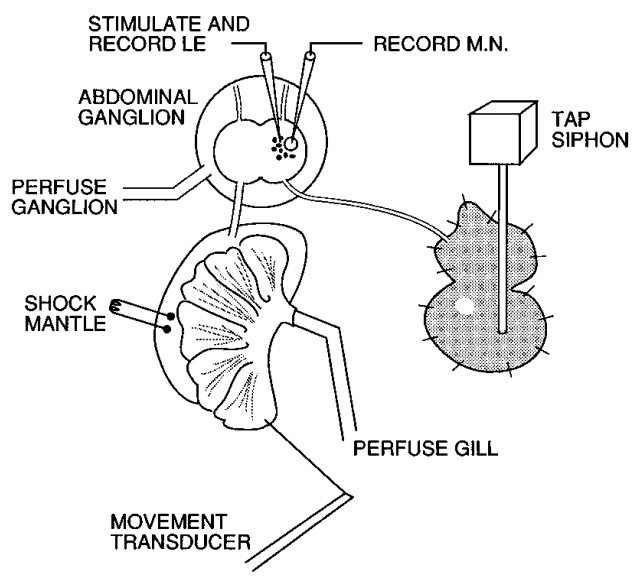

B

HABITUATION

DISHABITUATION

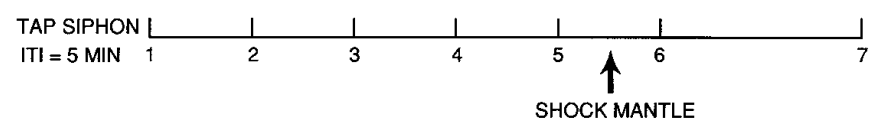

SENSITIZATION

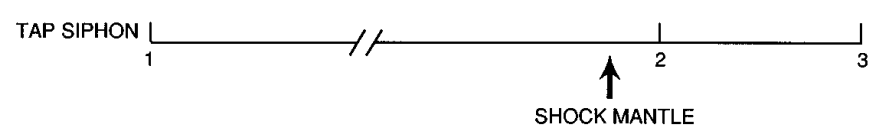

Figure 1. Experimental preparation $(A)$ and behavioral protocols $(B)$. For details, see Materials and Methods.

were dissected out in $50 \% \mathrm{MgCl}_{2}, 50 \%$ artificial seawater. The siphon was separated surgically from the gill, so that the reflex was mediated entirely through the ganglion via the siphon and branchial nerves (Fig. 1A). These experiments thus examined the central component of the reflex in isolation (cf. Lukowiak, 1977). The ganglion was dipped in $0.5 \%$ glutaraldehyde for $60 \mathrm{sec}$ to kill muscle cells in the sheath. The preparation was then pinned to the Sylgard floor of a Lucite recording chamber filled with circulating, aerated artificial seawater at room temperature, and the ganglion was partially desheathed. The gill was perfused with seawater through the afferent vein, and seawater was injected into the siphon to flush out the $\mathrm{MgCl}_{2}$.

The gill motor neuron LDG1, identified by its electrophysiological properties (Frazier et al., 1967) and characteristic gill movement (Kupfermann et al., 1974), was impaled with a single- or double-barreled glass microelectrode filled with $2.5 \mathrm{M} \mathrm{KCl}$. In some experiments, current was passed through one barrel of the electrode either to hyperpolarize the neuron $\sim 30 \mathrm{mV}$ below resting potential and prevent spiking during the siphon stimulation, or to depolarize the neuron and cause spiking. The siphon was stimulated with pressure (usually $\sim 23$ $\mathrm{gm} / \mathrm{mm}^{2}$ ) from a stainless steel rod (diameter $1.5 \mathrm{~mm}$ ) connected to a digital stepping motor (Haydon Switch Instruments, Waterbury, CT) with feedback control from a force sensor (Omega Engineering, Stamford, $\mathrm{CT}$ ). The stimulator was calibrated against a strain gauge transducer (Grass Instruments, Quincy, MA). The stimulus duration was $500 \mathrm{msec}$, to be consistent with experiments on classical conditioning in this preparation (Hawkins et al., 1993). Gill withdrawal was recorded with a low-mass isotonic transducer (Harvard Apparatus, South Natick, MA) connected to the efferent vein of the gill with a silk suture. During dishabituation and sensitization training, the mantle shelf was stimulated with a train of four $60 \mathrm{~Hz}$ AC electrical shocks (1.0 sec duration, $2 \mathrm{sec}$ ISI, $25 \mathrm{~mA}$ ) delivered via fixed capillary electrodes. Preparations were considered healthy and included in the results only if the shock produced a gill withdrawal of at least $5 \mathrm{~mm}$.

In some experiments the abdominal ganglion was surrounded by a circular well with the nerves led through a Vaseline seal, so that the ganglion could be perfused separately from the rest of the preparation.
The ganglion was then perfused with seawater, with elevated concentrations of $\mathrm{CaCl}_{2}$ (average $11.5 \mathrm{~mm}$ ) and $\mathrm{MgCl}_{2}$ (average $144 \mathrm{~mm}$ ) to raise the threshold for spike initiation of all neurons in the ganglion, thus blocking most of the polysynaptic component of the PSP in LDG1 when the siphon was stimulated. Trudeau and Castellucci (1992) found that a similar seawater solution reduces the amplitude of complex PSPs without altering unitary PSPs. This solution does not completely suppress spiking, however, so in a few experiments LDG1 was also slightly hyperpolarized $(\sim 10 \mathrm{mV})$ to prevent it from spiking during siphon stimulation and to permit measurement of the PSP. Preparations were considered healthy and included in the results only if the mantle shock produced firing of the gill motor neuron LDG1 (and presumably also other neurons in the ganglion, including facilitatory interneurons).

The preparation was rested for at least $1 \mathrm{hr}$ before the beginning of dishabituation or sensitization training (Fig. $1 B$ ). During habituation, the siphon was stimulated five times with a $5 \mathrm{~min}$ intertrial interval, and habituation was measured as the decrease in responding on trial 5 compared with trial 1 . The mantle was then shocked 2.5 min after trial 5 , and the siphon was stimulated again $2.5 \mathrm{~min}$ (trial 6) and $12.5 \mathrm{~min}$ (trial 7) after the shock. Dishabituation was measured as the increase in responding on trials 6 and 7, compared with trial 5. During sensitization, there was a single siphon stimulation (trial 1 ) followed by a $1 \mathrm{hr}$ rest to minimize habituation. The mantle was then shocked, and the siphon was stimulated again $2.5 \mathrm{~min}$ (trial 2) and $12.5 \mathrm{~min}$ (trial 3) after the shock. Sensitization was measured as the increase in responding on trials 2 and 3 , compared with trial 1 . On each trial we measured the gill withdrawal and the spikes or the complex PSP produced in the gill motor neuron LDG1 by siphon stimulation. The area of the PSP was calculated using a laboratory interface to a microcomputer and commercially available software (Spike, Hilal Associates, Englewood, NJ). The data on dishabituation and sensitization were first analyzed with a two-way ANOVA with one repeated measure (test time), and then individual comparisons were made using the error estimate from the ANOVA.

\section{RESULTS}

\section{Contribution of gill motor neuron LDG1 to the reflex}

Gill withdrawal is controlled by six identified central motor neurons, L7, L91, L92, LDG1, LDG2, and RDG, each of which mediates a different component of movement by innervating different gill muscles through different combinations of nerves (Carew et al., 1974; Kupfermann et al., 1974). Kupfermann et al. (1974) estimated that L7 and LDG1 each contribute $~ 35 \%$ of the gill-withdrawal reflex measured with a photocell in the intact animal. We expected that LDG1 would make a larger contribution in our preparation because our transducer measures contraction of the efferent vein, which is the major movement produced by LDG1, whereas a photocell is more sensitive to the pinnule contraction produced by L7. In addition, we cut all the nerves to the gill except the branchial nerve, which should eliminate the contribution of LDG2 and reduce the contribution of other motor neurons that have axons in the other nerves. To assess the quantitative contribution of LDG1 to the reflex response in the isolated mantle organ preparation, we first measured reflex withdrawal of the gill either under control conditions or with LDG1 hyperpolarized by intracellular current injection, which prevents spiking and effectively removes the neuron from the circuit. In the example shown in Figure $2 A$, hyperpolarization of LDG1 reduced the reflex response by $85 \%$. In eight similar experiments with an ABA design (counterbalanced for order), hyperpolarization of LDG1 reduced the response on average by $84 \pm 6 \%$ (SEM). The percentage reduction was correlated negatively with the size of the control response $(r=-0.97 ; p<0.01)$ (Fig. $2 B)$. These results indicate that LDG1 mediates most of the reflex response in this preparation and suggest that during larger responses other motor neurons also contribute.

We next examined the gill withdrawal produced by firing LDG1 with intracellular current injection. We wanted to mimic roughly the natural firing pattern of LDG1 illustrated in Figure $2 A$, which 
Figure 2. Contribution of LDG1 to the reflex response. $A$, Records from a representative experiment showing gill withdrawal in response to a siphon tap with LDG1 at resting potential (control) or hyperpolarized to prevent it from spiking. $B$, Percentage reduction in gill withdrawal when LDG1 was hyperpolarized compared with control (CONTRIBUTION LDG1) as a function of control gill-withdrawal amplitude in eight experiments like the one shown in $A$. Maximal gill withdrawal was $\sim 7.5 \mathrm{~mm}$ (see Fig. 5 legend). The siphon was tapped at $5 \mathrm{~min}$ intervals with LDG1 alternately at resting potential and hyperpolarized until the responses stabilized. In half of the experiments, a control response was compared with the average of the hyperpolarized responses before and after it (as shown in $A$ ), and in the other half of the experiments a hyperpolarized response was compared with the average of the control responses before and after it. The dashed line is the linear regression fitted to the data points.
A

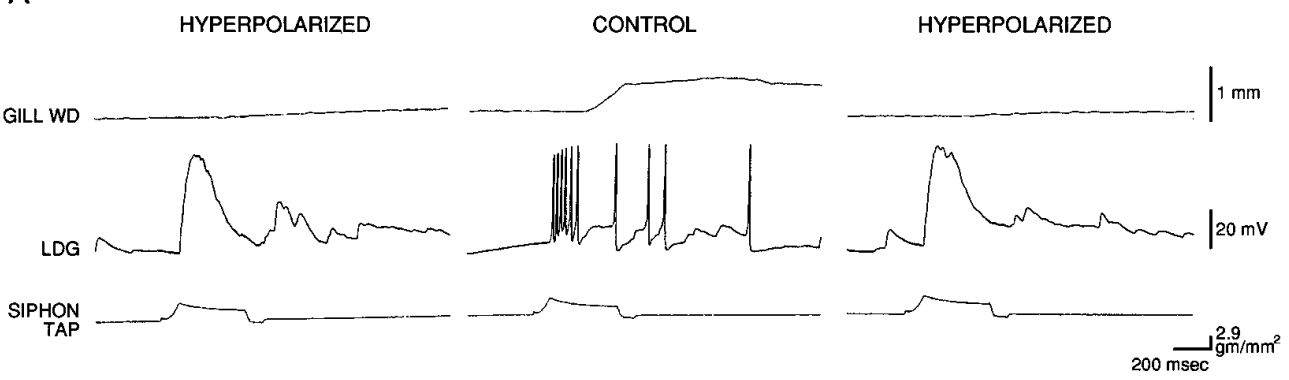

B

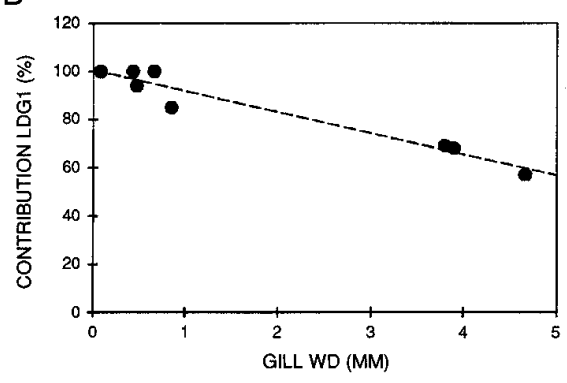

gill withdrawal for the shocked group was significantly greater than for the no-shock control group $\left(F_{(1,22)}=7.08 ; p<0.05\right)$. Similarly, a third group, which was not first habituated $(n=10)$, showed significant sensitization on trial 2, 2.5 min after the shock $\left(F_{(1,22)}=29.39 ; p<0.01\right)$ and on trial 3, 12.5 min after the shock $\left(F_{(1,22)}=47.38 ; p<0.01\right)$, compared with trial 1 . There were no significant changes in the time-to-peak of gill withdrawal (which averaged $1.2 \mathrm{sec}$ in these experiments) during habituation, dishabituation, or sensitization.

Figure 4 shows an example of the firing of LDG1 recorded simultaneously with gill withdrawal, and Figure $5 B$ shows the average evoked firing during the first $1.4 \mathrm{sec}$ after the start of the response to siphon stimulation, which included the peak of the gill withdrawal on most trials. There was a significant decrease in evoked firing of LDG1 in both habituation groups $\left(F_{(1,13)}=38.75\right.$; $p<0.01$; comparing trial 5 with trial 1$)$, which correlated significantly with the decrease in gill withdrawal $(r=0.68 ; p<0.01$; comparing trial 5 divided by trial 1 for gill withdrawal and evoked firing of LDG1). During dishabituation there was a significantly greater increase in evoked firing for the shocked group than for the no-shock control group $\left(F_{(1,22)}=8.92 ; p<0.01\right)$, which did not show any increase. On trial 7, $12.5 \mathrm{~min}$ after the shock, there was a significant increase in evoked firing of $\operatorname{LDG} 1\left(F_{(1,22)}=\right.$ 11.64; $p<0.01$, compared with trial 5), which correlated significantly with the increase in gill withdrawal $(r=0.85 ; p<0.01)$. On trial 6, $2.5 \mathrm{~min}$ after the shock, there was a smaller increase in evoked firing of LDG1, which was not significant and did not correlate significantly with the increase in gill withdrawal $(r=$ 0.03). Similarly, during sensitization, there was a significant increase in evoked firing of LDG1 on trial 3, 12.5 min after the shock $\left(F_{(1,22)}=15.81 ; p<0.01\right.$, compared with trial 1$)$, but there was a small decrease on trial 2, 2.5 min after the shock. Overall, during dishabituation and sensitization, there was a significantly greater increase in evoked firing of LDG1 12.5 min after the shock than 2.5 min after the shock $\left(F_{(1,22)}=13.88 ; p<0.01\right)$.

The results of these experiments suggest that habituation of the withdrawal reflex is largely attributable to a decrease in evoked firing of LDG1, and that dishabituation and sensitization $12.5 \mathrm{~min}$ indicating that there was little recovery from habituation during the $10 \mathrm{~min}$ rest between trials 6 and 7. Moreover, the increase in dishabituation on trial $6,2.5 \mathrm{~min}$ after the shock $\left(F_{(1,22)}=7.45\right.$; $p<0.05)$, and on trial 7, $12.5 \mathrm{~min}$ after the shock $\left(F_{(1,22)}=21.35\right.$; $p<0.01)$, compared with trial 5. The second group $(n=5)$, which was not shocked, did not show a significant increase on trial 7 , 
A

GILL WD

LDG

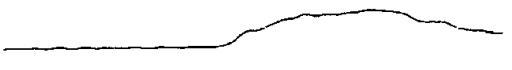

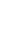
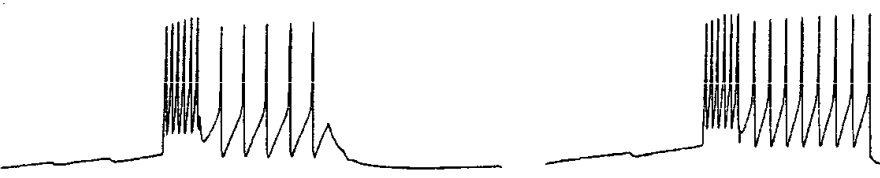

1 mm

CURRENT
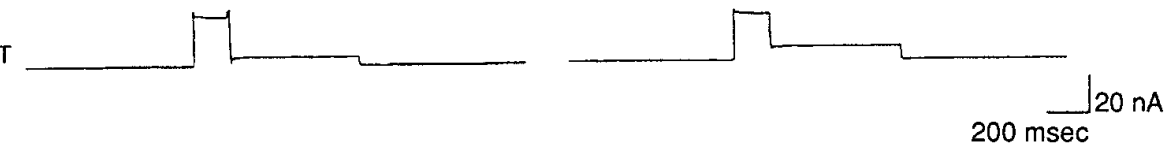

B
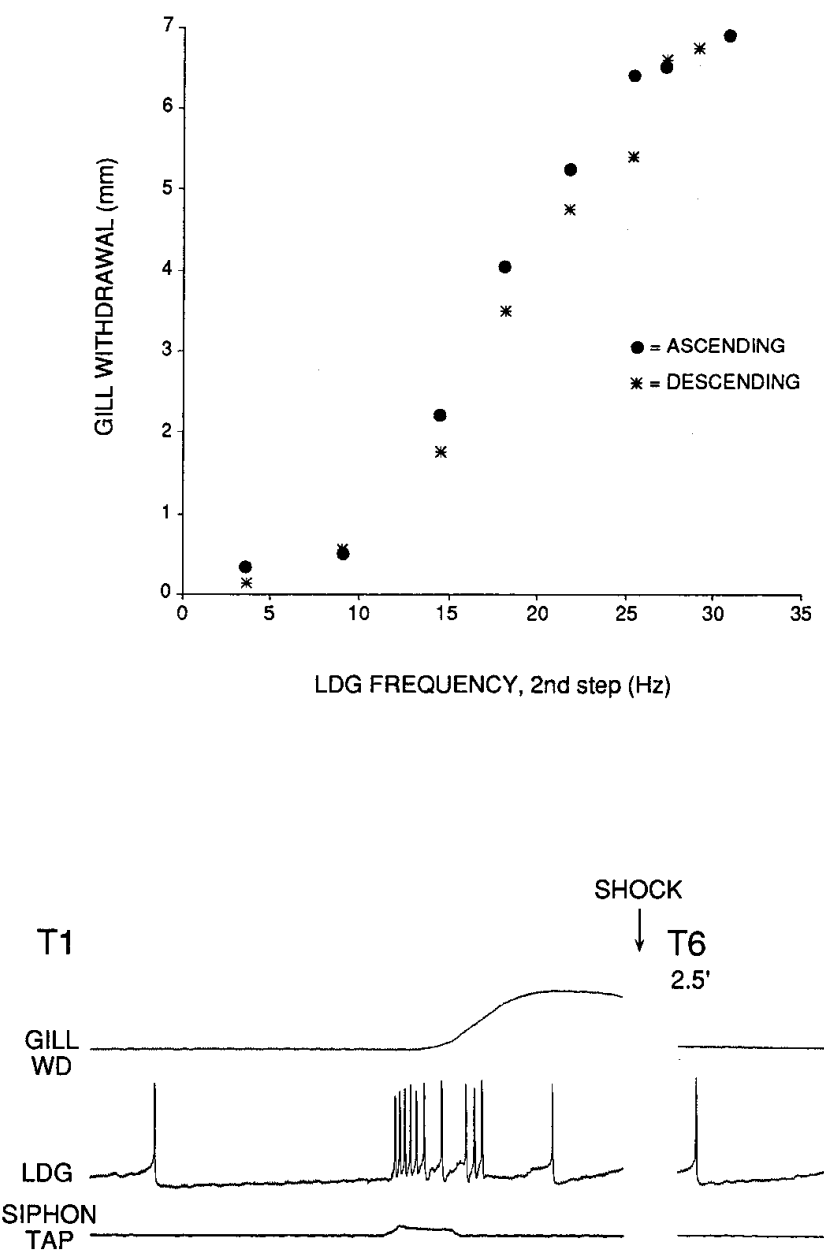

SHOCK
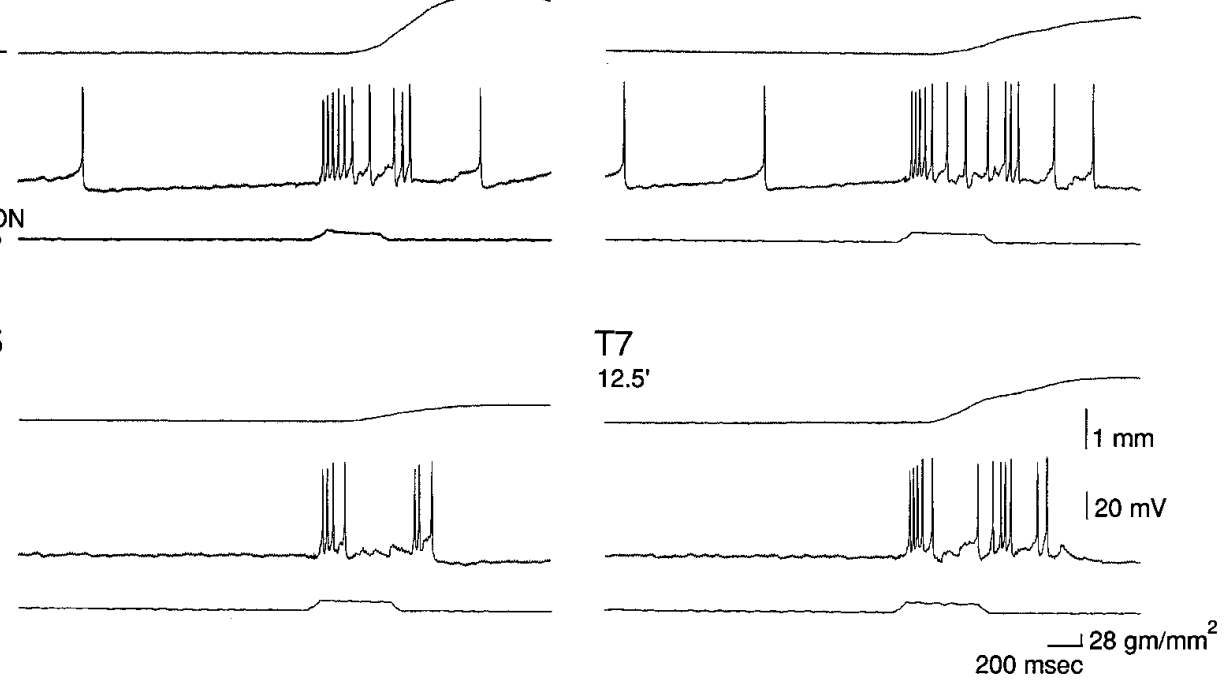

Figure 4. Example of gill withdrawal and firing of LDG1 on trials 1 (T1) and 5 (T5) during habituation, and trials 6 (T6) and 7 (T7), $2.5 \mathrm{~min}$ and $12.5 \mathrm{~min}$ after mantle shock during dishabituation. (See Fig. $1 B$ for the behavioral protocol.)

Figure 3. Gill withdrawal produced by firing LDG1 at different frequencies. $A$, Records from a representative experiment showing the gill withdrawal and G1 in response to a two(ith to mimic the physiological pattern of firing. $B$, Graph of data from the same experiment as in $A$. Gill withdrawal was tested at 1 min intervals, with first an ascending and then a descending series of current intensities during the second step. The records shown in $A$ correspond to the points at $9 \mathrm{~Hz}$ and $14.5 \mathrm{~Hz}$ during the second step $(15.7$ and $20 \mathrm{~Hz}$ overall), which are within the physiological range of firing of LDG1. 

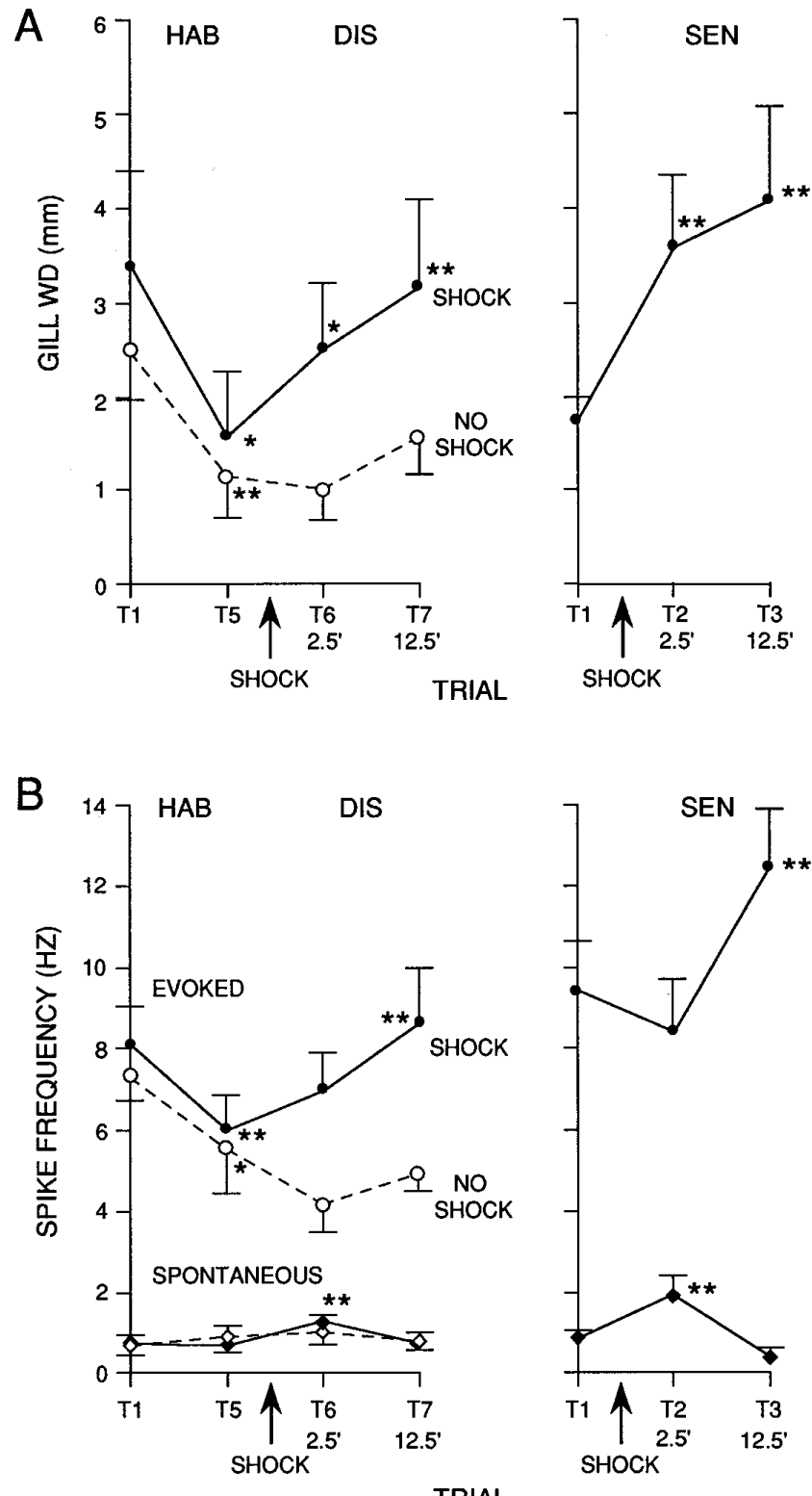

TRIAL

Figure 5. Average gill withdrawal and firing of LDG1 during habituation $(H A B)$ and dishabituation $(D I S)$ in 10 experiments like the one shown in Figure 4, and during sensitization (SEN) in 10 additional experiments. $A$, Peak amplitude of gill withdrawal in response to siphon stimulation in the groups receiving mantle shock (solid line) and a no-shock control group (dashed line, $n=5$ ). The average amplitude of gill withdrawal in response to the mantle shock was $7.6 \pm 0.5 \mathrm{~mm}(n=20)$, which was near maximal contraction. $B$, Frequency of firing of LDG1 measured simultaneously with the gill withdrawals shown in $A$. Spontaneous firing is the average rate during the $5 \mathrm{sec}$ before each siphon stimulation, and evoked firing is the average rate during the first $1.4 \mathrm{sec}$ after the start of the response in LDG1 minus the spontaneous rate on that trial. In this and subsequent graphs the points indicate the mean, and the vertical bars indicate the SEM. ${ }^{* *}=p<$ $0.01 ; *=p<0.05 ;+=p<0.05$, one-tail compared with pretraining control (trial 1 for habituation and sensitization, trial 5 for dishabituation).

after the shock are attributable at least in part to an increase in evoked firing of LDG1. Dishabituation and sensitization $2.5 \mathrm{~min}$ after the shock, however, evidently cannot be accounted for by changes in the average evoked firing of LDG1. One possible explanation for this discrepancy is that other motor neurons fire disproportionately more than LDG1 2.5 min after the shock.
When LDG1 was removed from the circuit by hyperpolarizing it (see below), however, habituation, dishabituation, and sensitization of the residual gill withdrawal were normal, suggesting that the remaining gill-motor neurons fire similarly to LDG1 (data not shown). A second possibility is that there is a change in the pattern of firing of LDG1, such that the same number of spikes produce greater gill withdrawal $2.5 \mathrm{~min}$ after shock. As shown in the example in Figure 4 and the average results in Figure 6, the evoked firing of LDG1 on each trial tended to follow a reproducible pattern with four components: an initial, high-frequency burst, a sustained response during the tap, a smaller second burst around the offset of the tap, and a gradual decline in firing after the tap. The second burst was time-locked to the end of the tap when tap duration was varied (Fig. 7), demonstrating that it is an off response and not simply a delayed onset response. The four components of the response did not always change together during habituation, dishabituation, and sensitization, suggesting that to some extent they involve different inputs onto the motor neuron (Fig. 6). For example, the initial burst was more stable than the other components during habituation, suggesting that it may include a contribution from a nonplastic interneuron. A relatively stable initial burst has also been observed in inhibitory motor neurons in crayfish (Hawkins and Bruner, 1981) and in both motor neurons (Hammond, 1954) and pyramidal tract neurons (Evarts, 1973) in primates, and may serve to overcome the inertia of the system and prime it to respond to the later components of the response (Fig. 3). There did not appear to be any change, however, in the pattern of firing of LDG1 during dishabituation and sensitization that could account for the increase in gill withdrawal $2.5 \mathrm{~min}$ after shock.

Another possible explanation is that there is peripheral enhancement, perhaps attributable to post-tetanic potentiation (PTP) at the neuromuscular junction. PTP is known to occur at the neuromuscular junction of LDG1 and has been suggested to contribute to dishabituation of the gill-withdrawal reflex (Jacklet and Rine, 1977). Consistent with that possibility, there were changes in spontaneous as well as evoked firing of LDG1 during dishabituation and sensitization (Figs. 4, 5B). During dishabituation there was a significant increase in spontaneous firing measured just before trial 6, $2.5 \mathrm{~min}$ after the shock $\left(F_{(1,22)}=8.53\right.$; $p<0.01$, compared with trial 5), which had worn off by trial $7,12.5$ min after the shock. The no-shock control group did not show any change in spontaneous firing. Similarly, during sensitization, there was a significant increase in spontaneous firing on trial 2, $2.5 \mathrm{~min}$ after the shock $\left(F_{(1,22)}=24.60 ; p<0.01\right)$, which had worn off by trial 3, $12.5 \mathrm{~min}$ after the shock. Overall, during dishabituation and sensitization there was a significantly greater increase in spontaneous firing of LDG1 2.5 min after the shock than $12.5 \mathrm{~min}$ after the shock $\left(F_{(1,22)}=22.56 ; p<0.01\right)$. These changes in spontaneous firing could give rise to peripheral enhancement 2.5 min after the shock.

\section{Peripheral enhancement contributes to dishabituation and sensitization}

We tested peripheral enhancement by measuring the gill withdrawal produced by intracellular stimulation of LDG1 after each siphon tap during habituation, dishabituation, and sensitization (Fig. 8). We used a two-step constant current injection like that shown in Figure 3 to mimic roughly the natural firing pattern of LDG1. During habituation there was a small decrease in gill withdrawal that is probably attributable to fatigue but is not sufficient to account for habituation of the response 


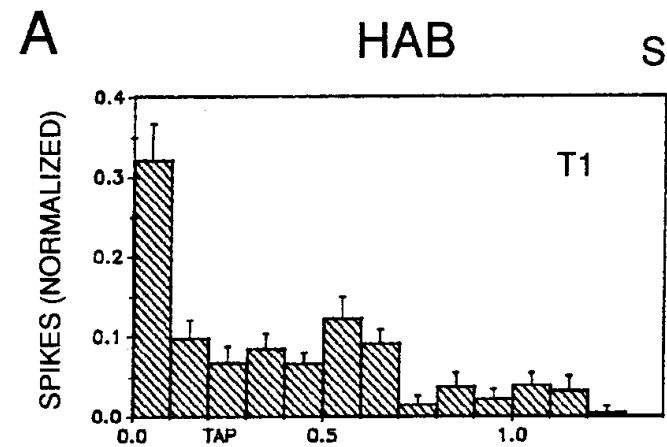

Shock
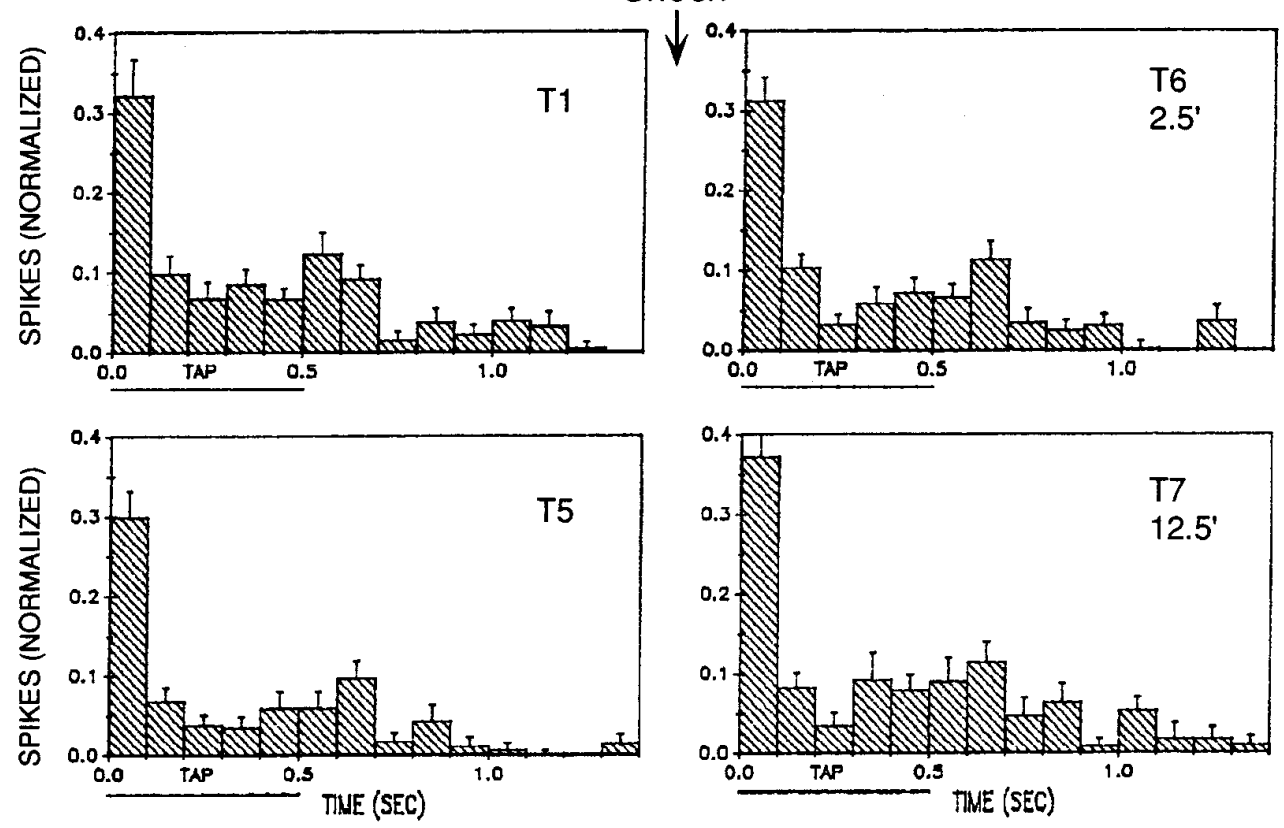

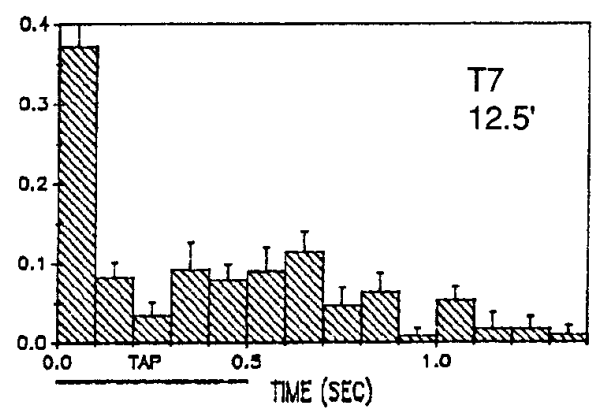

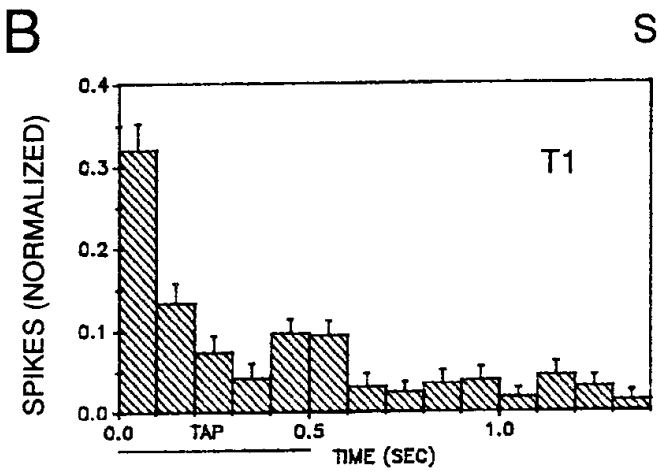

嵌
Shock
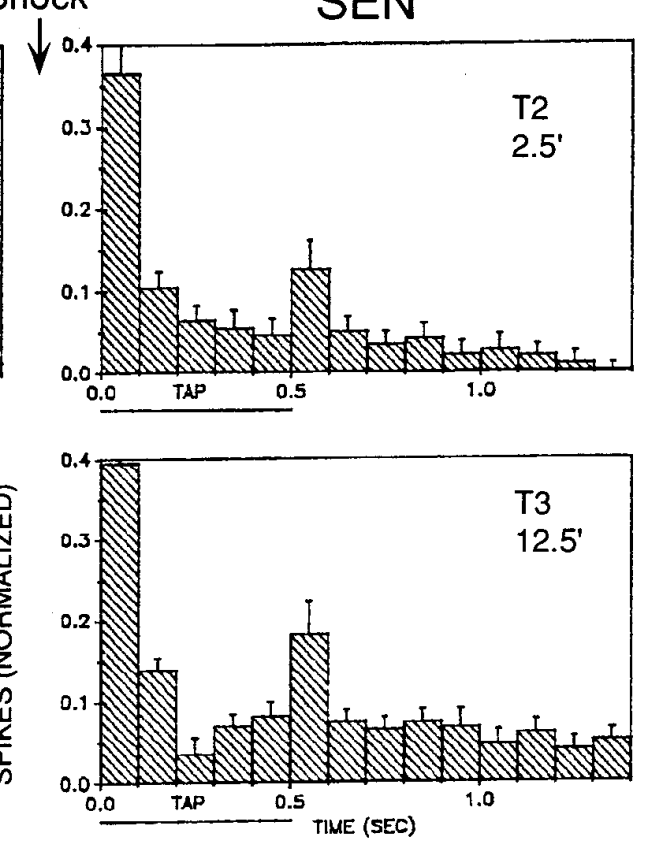

Figure 6. Average pattern of evoked firing of LDG1 on each trial during habituation, dishabituation, and sensitization of the withdrawal reflex in the same experiments as Figure 5. A, Trials 1 (T1) and 5 (T5) during habituation, and trials 6 (T6) and 7 (T7), $2.5 \mathrm{~min}$ and 12.5 min after mantle shock during dishabituation. $B$, Trials $1,2(T 2)$, and 3 (T3), $2.5 \mathrm{~min}$ and $12.5 \mathrm{~min}$ after mantle shock during sensitization. On each trial, the number of spikes in each 100 msec interval (minus the number expected from spontaneous firing on that trial) has been normalized to the total number of evoked spikes on trial 1 in each experiment. The horizontal bar below the $x$-axis indicates the duration of the siphon tap. to siphon stimulation. Byrne et al. (1978a) obtained similar results when they recorded gill withdrawal with a photo cell, but they reported a much larger decrease when they recorded with a strain gauge. We probably observed minimal fatigue because (1) our low-mass movement transducer offers less resistance than a strain gauge, and (2) we tested with a low frequency of siphon stimulation. By contrast, during dishabituation there was a significant increase in gill withdrawal measured just after trial 6, 2.5 min after the shock $\left(n=10 ; F_{(1,16)}\right.$ $=70.97 ; p<0.01$, compared with trial 5), which had partially worn off by trial 7, $12.5 \mathrm{~min}$ after the shock. Similarly, during sensitization there was a significant increase in gill withdrawal on trial 2, $2.5 \mathrm{~min}$ after the shock $\left(n=8 ; F_{(1,16)}=21.49 ; p<\right.$ 0.01 , compared with trial 1 ), which had partially worn off by trial 3, 12.5 min after the shock. Overall, during dishabituation and sensitization there was a significantly greater increase in gill withdrawal 2.5 min after the shock than 12.5 min after the shock $\left(F_{(1,16)}=11.28 ; p<0.01\right)$. These results indicate that peripheral enhancement contributes to dishabituation and sensitization of gill withdrawal $2.5 \mathrm{~min}$ after the shock, and to a lesser extent $12.5 \mathrm{~min}$ after the shock.

As shown in Figure $8 B$, there was no change in the number of 
$\mathrm{A} 1$
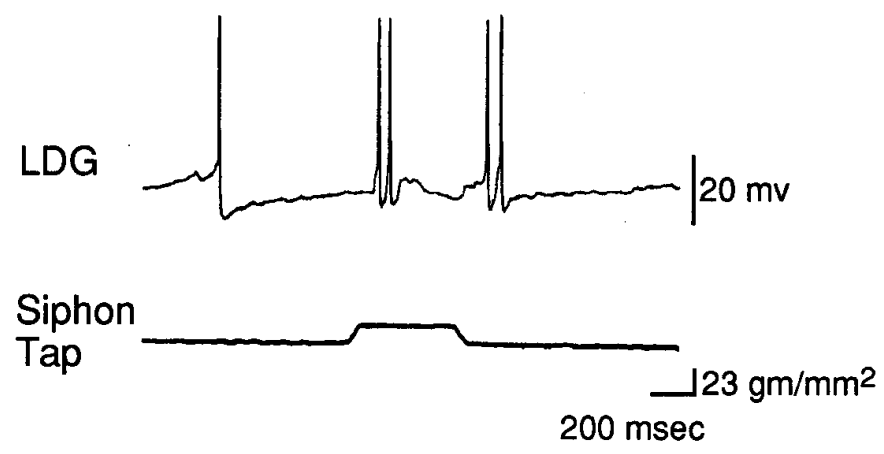

$\mathrm{A} 2$

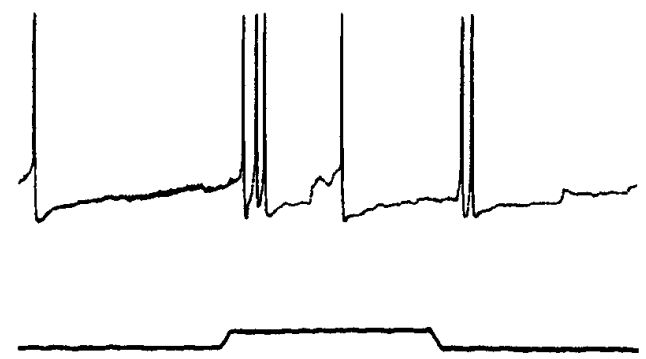

B1

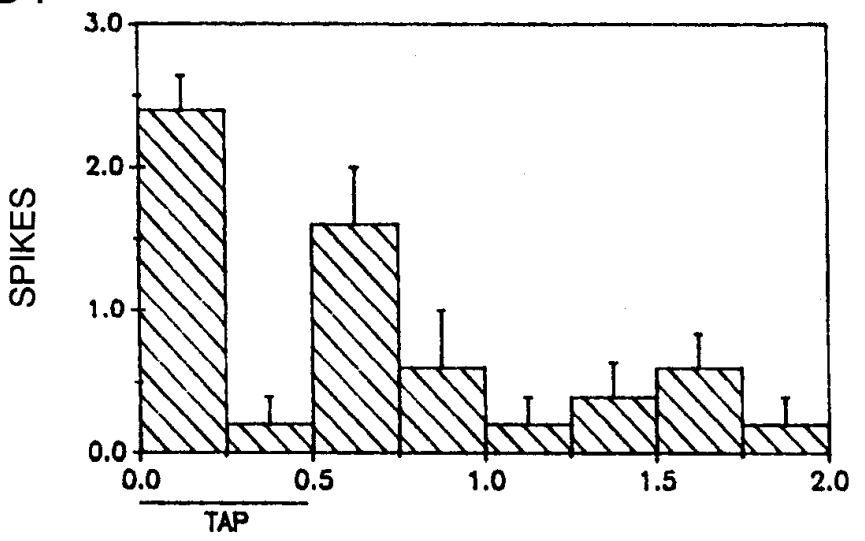

B2

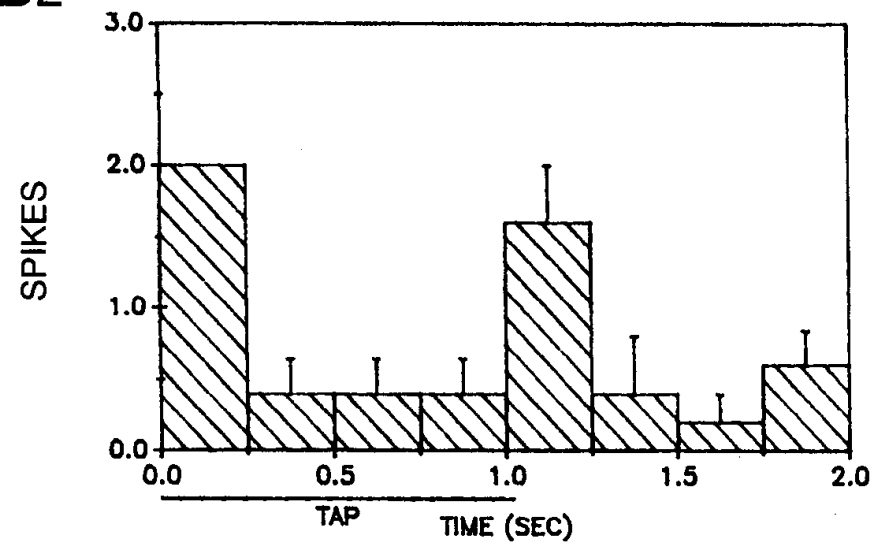

Figure 7. Firing of LDG1 in response to siphon taps of different durations. $A$, Records from a representative experiment showing firing of LDG1 in response to siphon taps of $500 \mathrm{msec}(A 1)$ and $1 \mathrm{sec}(A 2) . B$, Average pattern of firing of LDG1 in the experiment shown in $A$. The siphon was stimulated with alternating taps of $500 \mathrm{msec}(B 1)$ or $1 \mathrm{sec}(B 2)$ duration at $5 \mathrm{~min}$ intervals for $45 \mathrm{~min}$. The histogram shows the average number of spikes in each $250 \mathrm{msec}$ interval. The horizontal bar indicates the duration of the tap. There was consistently a second burst of firing at the offset of the tap.

spikes produced in LDG1 by constant current injection during habituation, dishabituation, and sensitization. This result indicates that the excitability of LDG1 was relatively constant, and therefore that changes in the number of spikes produced by siphon stimulation during habituation, dishabituation, and sensitization (Figs. 4, 5B) were attributable to changes in synaptic input.

The complex PSP in LDG1 during habituation, dishabituation, and sensitization

We directly tested the possibility that habituation, dishabituation, and sensitization involve changes in synaptic input to LDG1 by hyperpolarizing LDG1 during the siphon tap, preventing it from firing and allowing measurement of the underlying complex PSP. As shown in the example in Figure $9 A$ and the average results in Figure 10, the complex PSP in LDG1 had a complicated shape, with the same four components that were described previously for evoked spikes: an initial peak near the onset of the tap, a smaller sustained depolarization during the tap, a second peak around the offset of the tap, and a gradual decline after the tap. We therefore measured the total area under the PSP in the first $1.4 \mathrm{sec}$ (Fig. $9 B)$. During habituation there was a significant decrease in the area of the PSP $\left(n=10 ; t_{(9)}=7.41 ; p<0.01\right.$, comparing trial 5 with trial 1). During dishabituation there was a small decrease on trial $6,2.5$ min after the shock, but a significant increase on trial $7,12.5 \mathrm{~min}$ after the shock $\left(F_{(1,16)}=27.17 ; p<0.01\right.$, compared with trial 5). During sensitization there was a significant decrease on trial 2, $2.5 \mathrm{~min}$ after the shock $\left(n=8 ; F_{(1,16)}=21.43 ; p<0.01\right.$, compared with trial 1), and no change on trial $3,12.5 \mathrm{~min}$ after the shock. Overall, during dishabituation and sensitization there was a significantly greater increase in the area of the PSP $12.5 \mathrm{~min}$ after the shock than 2.5 min after the shock $\left(F_{(1,16)}=33.53 ; p<\right.$ 0.01 ). Moreover, there was a significantly greater increase (or smaller decrease) during dishabituation than during sensitization $\left(F_{(1,16)}=8.94 ; p<0.01\right)$.

\section{The monosynaptic component of the PSP in LDG1 during habituation, dishabituation, and sensitization}

Changes in the complex PSP in LDG1 could be attributable to changes in either the monosynaptic input from the sensory neurons, the polysynaptic input via interneurons, or both. To examine the monosynaptic component of the PSP in isolation, we perfused the abdominal ganglion with seawater containing elevated concentration of $\mathrm{Ca}^{2+}$ and $\mathrm{Mg}^{2+}$ (" $\mathrm{Hi} \mathrm{Ca}^{2+}, \mathrm{Hi} \mathrm{Mg}^{2+}$ ), which raises the threshold for spike initiation and blocks most of the polysynaptic component of the PSP by preventing interneurons from firing. As illustrated in Figures $11 A$ and 12, the PSP generally had 


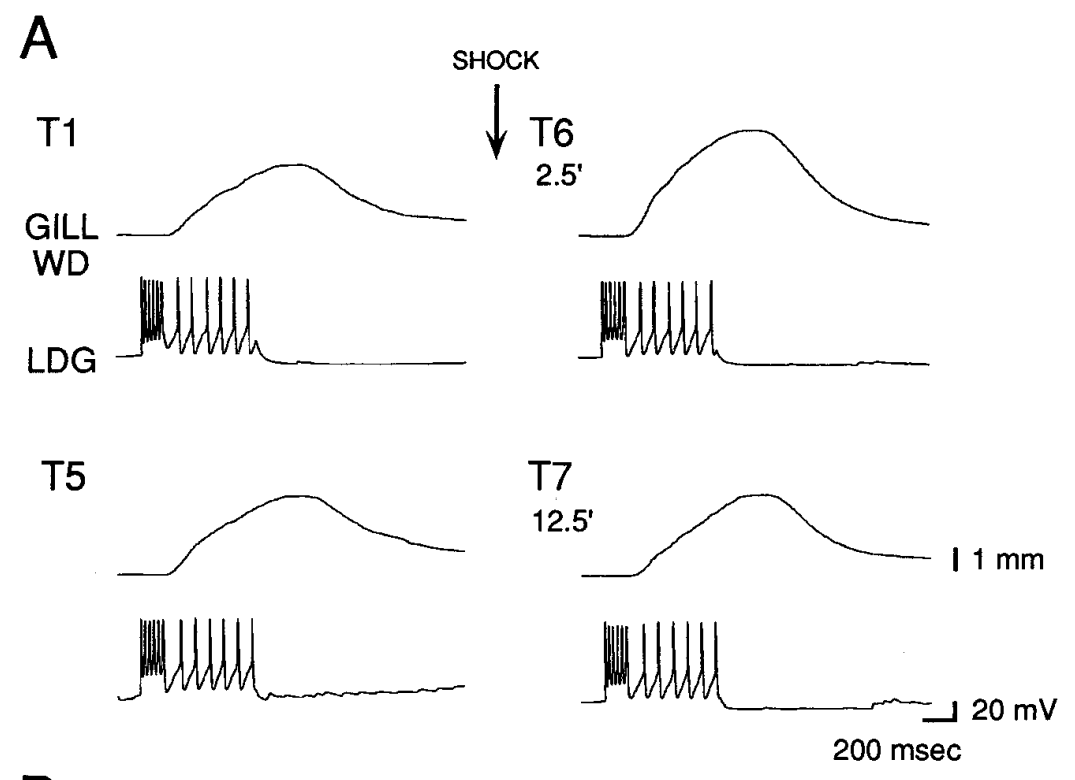

B

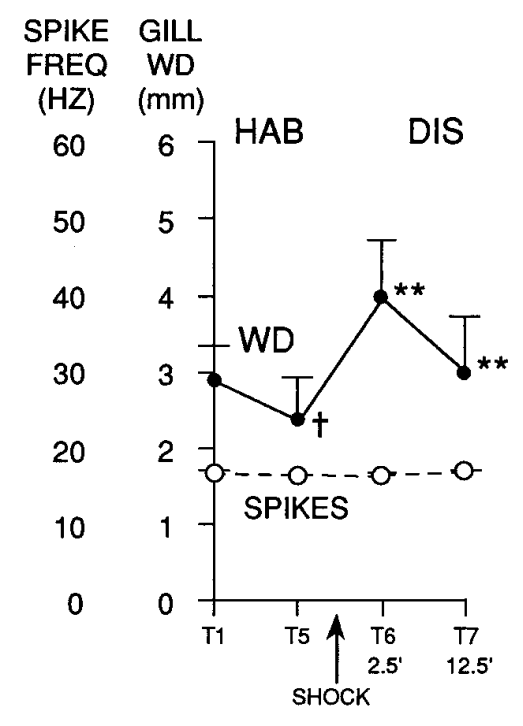

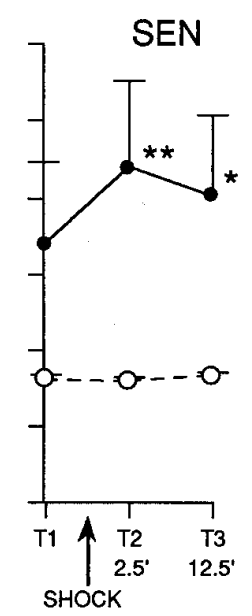

TRIAL
Figure 8 . Gill withdrawal produced by intracellular stimulation of LDG1 during habituation, dishabituation, and sensitization. $A$, Records from a representative experiment showing the gill withdrawal produced by firing LDG1 with a two-step constant current injection during habituation and dishabituation. $B$, Average gill withdrawal and firing of LDG1 during habituation and dishabituation in 10 experiments like the one shown in $A$, and during sensitization in eight additional experiments. Depolarizing current was injected into LDG1 $\sim 30 \mathrm{sec}$ after each siphon tap in the experiments shown in Figure 9. Solid line indicates gill withdrawal; dashed line indicates average spike frequency during current injection in LDG1. a relatively simple shape, consistent with its being predominantly monosynaptic. The PSP often had visible inflections, which could be individual unitary PSPs produced by firing of sensory neurons at different times after the start of the tap (Frost et al., 1997). There was significant habituation of the PSP on trial $5\left(n=8 ; t_{(7)}\right.$ $=8.25 ; p<0.01$, compared with trial 1) and significant dishabituation on trial 6, $2.5 \mathrm{~min}$ after the shock $\left(F_{(1,14)}=6.18 ; p<0.05\right.$, compared with trial 5), which had largely worn off by trial $7,12.5$ min after the shock (Fig. 11B). Similarly, there was significant sensitization of the PSP on trial 2, 2.5 min after the shock $(n=8$; $F_{(1,14)}=31.46 ; p<0.01$, compared with trial 1$)$, which had partially worn off by trial $3,12.5$ min after the shock. Overall, during dishabituation and sensitization there was a significantly greater increase in the area of the PSP $2.5 \mathrm{~min}$ after the shock than 12.5 min after the shock $\left(F_{(1,14)}=5.86 ; p<0.05\right)$, which is the reverse of the results in normal seawater (Fig. 9). Furthermore, in $\mathrm{Hi} \mathrm{Ca}^{2+}, \mathrm{Hi} \mathrm{Mg}^{2+}$ seawater (unlike normal seawater), there was no significant difference between dishabituation and sensitization.

\section{DISCUSSION}

We began a cellular analysis of simple forms of learning of the gill-withdrawal reflex by first establishing critical elements in the neural circuit for the reflex in the isolated mantle organ preparation. Our results show that the gill motor neuron LDG1 mediates most of the reflex response in this preparation, so that changes in firing of LDG1 can be related causally to changes in behavior. During habituation, and also during dishabituation and sensitization 12.5 min after the shock, changes in evoked firing of LDG1 (Fig. $5 B$ ) are similar to (and can largely account for) changes in gill withdrawal (Fig. $5 A$ ), in agreement with previous studies on preparations in which a single motor neuron makes less of a contribution to gill withdrawal (Kupfermann et al., 1970; Jacklet and Rine, 1977). Peripheral enhancement (perhaps caused by PTP at the neuromuscular junction), however, makes a substantial contribution to dishabituation and sensitization $2.5 \mathrm{~min}$ after the shock (Fig. 8). Peripheral enhancement has also been shown to contribute to classical conditioning of the gill-withdrawal reflex 
NORMAL ASW

SHOCK

T1 $\downarrow$ T6

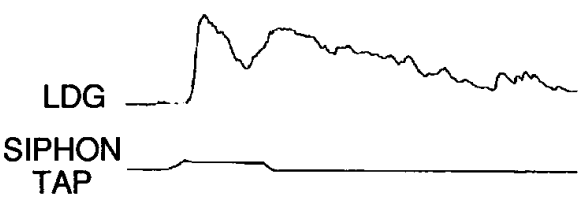

$2.5^{\prime}$

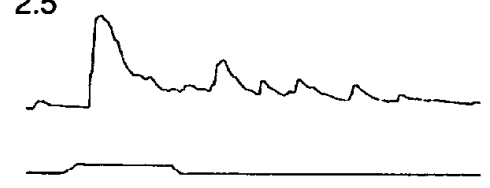

T5
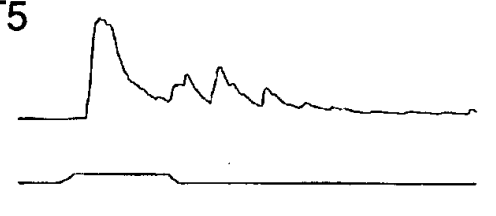

B

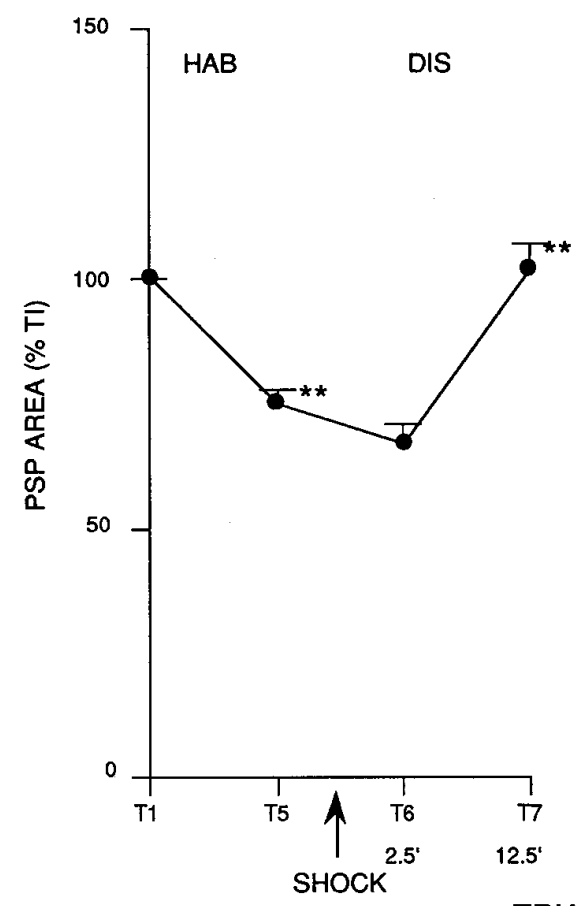

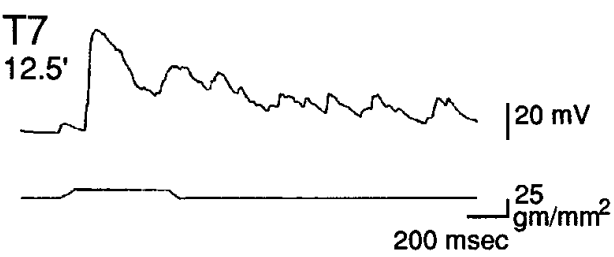

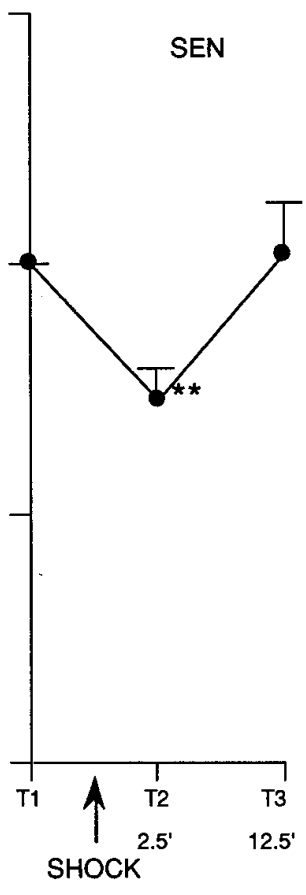

Figure 9. The complex PSP produced in LDG1 by siphon stimulation during habituation, dishabituation, and sensitization. $A$, Records from a representative experiment showing the complex PSP during habituation and dishabituation. LDG1 was hyperpolarized $\sim 40 \mathrm{mV}$ below resting potential to keep it from firing during each siphon tap. $B$, Average area of the PSP during habituation and dishabituation in 10 experiments like the one shown in $A$, and during sensitization in eight additional experiments. PSP area was measured during the first $1.4 \mathrm{sec}$ after the start of the PSP and was normalized to the area on trial 1 in each experiment (average on trial $1=$ 23,309 $\mathrm{mVmsec}$ for the habituation experiments and $11,599 \mathrm{mVmsec}$ for the sensitization experiments).

TRIAL

(Lukowiak and Colebrook, 1988), and PTP at neuromuscular junctions is thought to contribute to both sensitization of the siphon component of the withdrawal reflex (Frost et al., 1988) and dishabituation of the crayfish claw-opening response (Hawkins and Bruner, 1981). Additional experiments will be necessary to determine whether the peripheral enhancement in our experiments is attributable to PTP at the neuromuscular junction or to other possible mechanisms, such as neuromodulatory effects.

\section{Comparison of evoked firing and the complex PSP in LDG1}

During habituation and dishabituation, changes in the complex PSP in LDG1 (Fig. 9B) are basically similar to (and can largely account for) changes in evoked firing (Fig. 5B), in agreement with earlier reports (Kupfermann et al., 1970; Byrne et al., 1978b).
During sensitization, however, the complex PSP undergoes relatively more inhibition and less facilitation than evoked firing of the motor neuron. There is a significant decrease in PSP area 2.5 min after shock during sensitization, which reveals an underlying transient inhibition that is present but less pronounced in evoked spiking (Fig. 5B). A similar transient inhibition has been reported for the siphon component of the withdrawal reflex both behaviorally (Mackey et al., 1987; Marcus et al., 1988) and cellularly (Wright et al., 1991) but is not seen behaviorally for the gill component (Hawkins et al., 1990) (Fig. 5A). These results therefore suggest that the gill and siphon components both undergo transient inhibition at the level of the central synapses, but the gill component does not express the inhibition behaviorally because of strong peripheral enhancement (Fig. 8). 

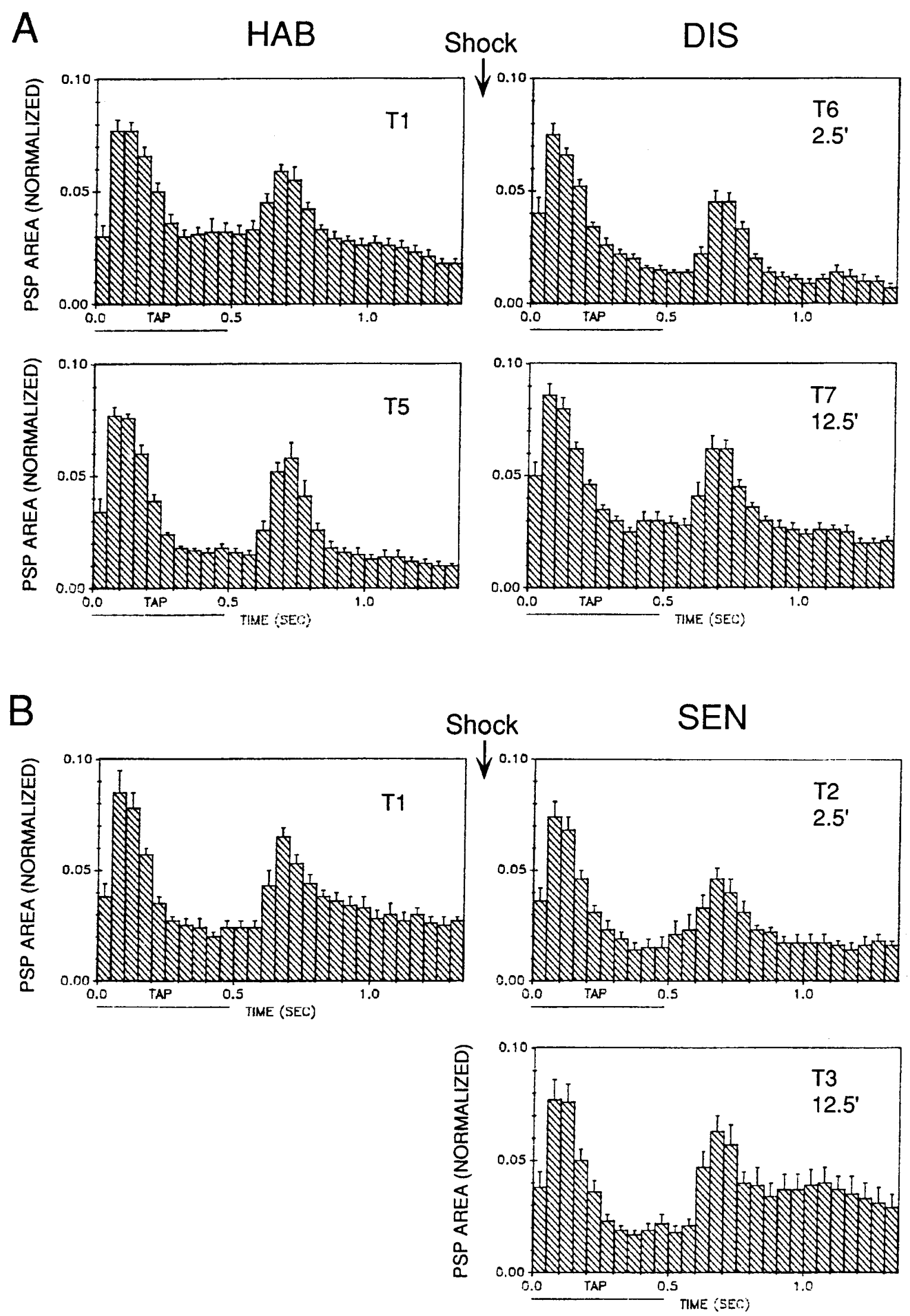

Figure 10. Average shape of the complex PSP produced in LDG1 by siphon stimulation during habituation and dishabituation $(A)$ and sensitization $(B)$ in the same experiments as Figure $9 B$. The PSP in each $50 \mathrm{msec}$ interval has been normalized to the total area on trial 1 in each experiment. The horizontal bar below the $x$-axis indicates the duration of the siphon tap. 


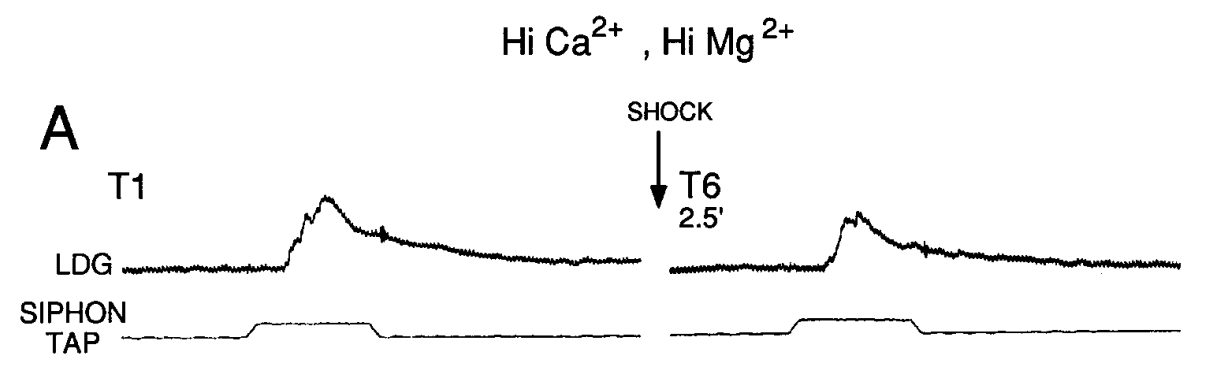

Figure 11. The monosynaptic component of the PSP in LDG1 during habituation, dishabituation, and sensitization. The abdominal ganglion was perfused with seawater containing elevated concentrations of $\mathrm{Ca}^{2+}$ and $\mathrm{Mg}^{2+}$, which blocks most of the polysynaptic component of the PSP. $A$, Records from a representative experiment showing the PSP in $\mathrm{Hi} \mathrm{Ca}{ }^{2+}, \mathrm{Hi}$ $\mathrm{Mg}^{2+}$ seawater during habituation and dishabituation. $B$, Average results from eight dishabituation experiments like the one shown in $A$, and eight sensitization experiments. The area under the PSP was measured during the first 1.4 sec after the start of the PSP and was normalized to the value on trial 1 in each experiment (the average on trial 1 was $5519 \mathrm{mVmsec}$ in the habituation experiments and $2314 \mathrm{mVmsec}$ in the sensitization experiments).

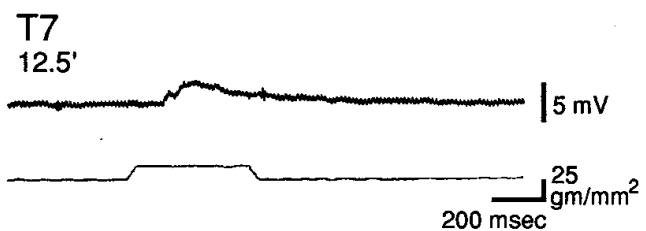

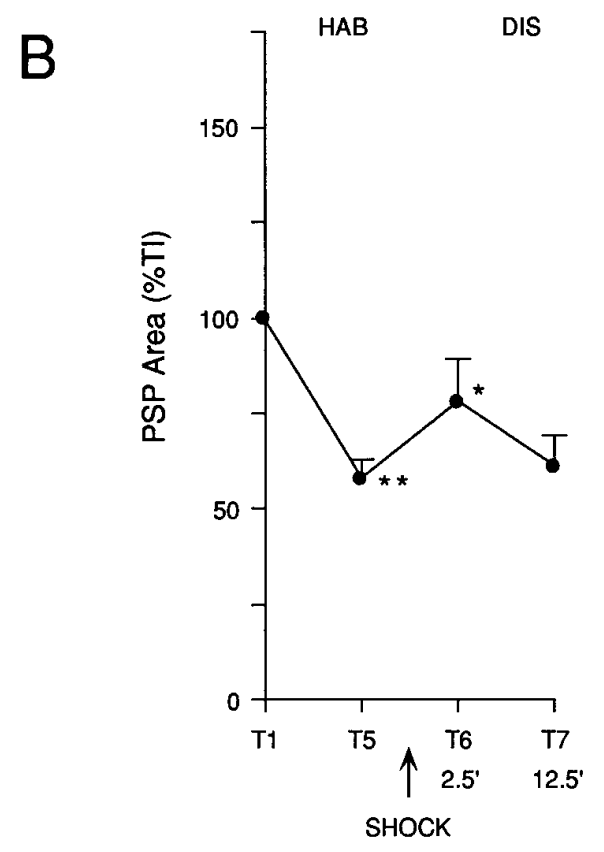

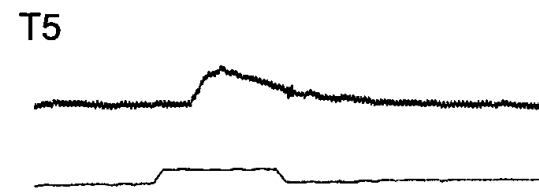

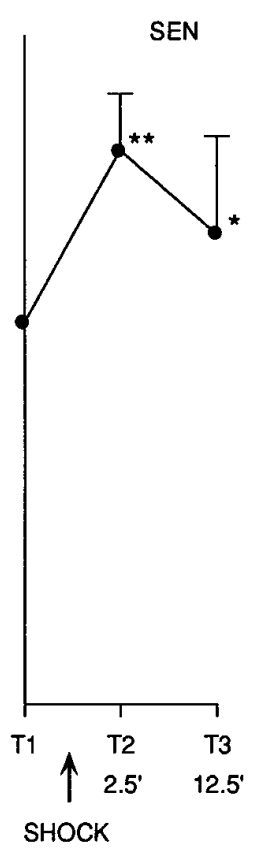

TRIAL
Similarly, there is no increase in PSP area $12.5 \mathrm{~min}$ after the shock during sensitization (Fig. 9), whereas there is a significant increase in evoked spikes (Fig. 5B). One possible explanation for these discrepancies is that the complex PSP includes both EPSPs and IPSPs, which are inverted when the cell is hyperpolarized. Thus, if there were a decrease in the IPSPs (disinhibition) and an increase in the EPSPs, there would be no change in the complex PSP when the cell was hyperpolarized, but an increase in evoked spikes when it was not. Disinhibition (inhibition of inhibitory neurons) occurs during a cellular analog of sensitization in the siphon component of the reflex (Frost et al., 1988; Trudeau and Castellucci, 1993) and during dishabituation of the crayfish clawopening response (Hawkins and Bruner, 1981).

The complex PSP has the same four components as evoked spiking (Fig. 10); however, the second peak tends to be more prominent for the PSP than for the spikes, suggesting that it contains IPSPs as well as EPSPs. As was the case for evoked spikes, the four components of the complex PSP did not always change together during habituation, dishabituation, and sensitization. For example, the initial peak again was more stable than the other components during habituation. Moreover, the complex PSP did not always change in the same way as the evoked spikes. For example, there was an increase in the second peak of evoked spikes but a decrease or no change in the second peak of the PSP during sensitization, suggesting that there were decreases in IPSPs in that component.

\section{Comparison of the complex PSP in normal seawater and $\mathrm{Hi} \mathrm{Ca}{ }^{2+}$, $\mathrm{Hi} \mathrm{Mg}{ }^{2+}$ seawater}

On average, the total area of the PSP on trial 1 in $\mathrm{Hi} \mathrm{Ca}^{2+}$, $\mathrm{Hi}$ $\mathrm{Mg}^{2+}$ seawater (Fig. 11) was $21 \%$ of the area in normal seawater (Fig. 9). This number provides an estimate of the percentage of 

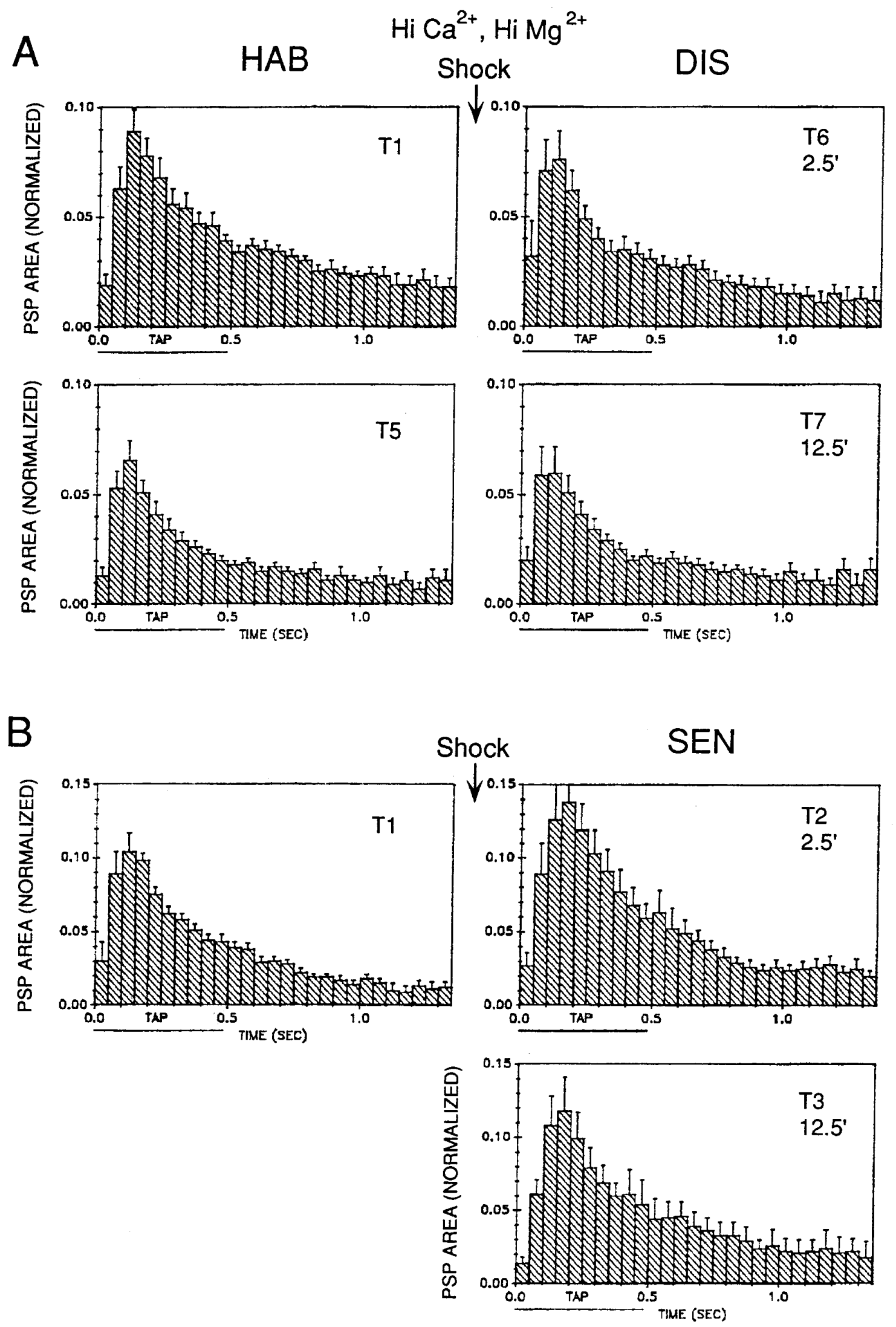

Figure 12. Average shape of the complex PSP produced in LDG1 by siphon stimulation during habituation and dishabituation $(A)$ and sensitization $(B)$ in the same experiments as Figure $11 B$. The PSP area in each $50 \mathrm{msec}$ interval has been normalized to the total area on trial 1 in each experiment. The horizontal bar below the $x$-axis indicates the duration of the siphon tap. 
Figure 13. Simplified neuronal circuit for the gillwithdrawal reflex illustrating some of the conclusions and inferences that can be drawn from our results concerning mechanisms of habituation, dishabituation, and sensitization. $S N$, Sensory neuron; $M N$, motor neuron; $I N T$, interneuron; $F A C$, facilitatory interneuron; $I N H$, inhibitory interneuron; depress, homosynaptic depression. The numbers in parentheses indicate the times after mantle shock that facilitation ( facil) or inhibition (inhib) are thought to occur at different sites in the circuit. For details, see Discussion.

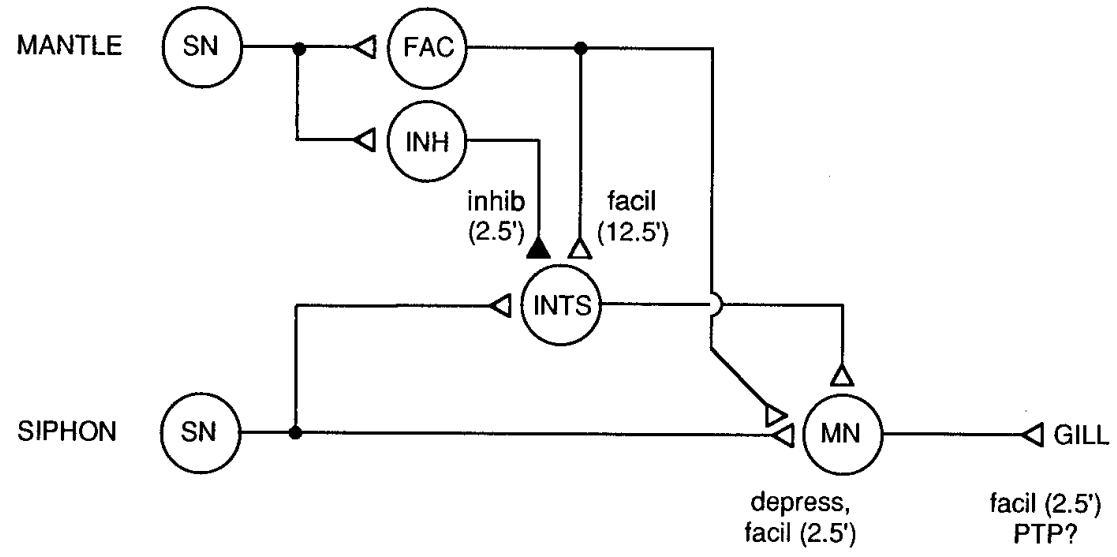

the PSP that is attributable to monosynaptic connections from sensory neurons to LDG1. This estimate is lower than the original estimate of $58 \%$ by Byrne et al. (1978b), but it is similar to the estimate of $25 \%$ by Trudeau and Castellucci (1992), who showed that a $\mathrm{Hi} \mathrm{Ca}^{2+}, \mathrm{Hi} \mathrm{Mg}^{2+}$ seawater solution similar to the one we used does not alter the amplitude of unitary PSPs, and therefore should provide a rough estimate of the contribution of monosynaptic PSPs to the complex PSP. Twenty-one percent could be an underestimate, however, because we compared monosynaptic PSPs at resting potential and complex PSPs with the motor neuron hyperpolarized, which increases the size of PSPs. Consistent with this possibility, a more direct comparison suggests that monosynaptic PSPs from sensory neurons make a larger contribution to the complex PSP (Frost et al., 1997).

Two differences are apparent in the shape of the complex PSP in $\mathrm{Hi} \mathrm{Ca}^{2+}$, $\mathrm{Hi} \mathrm{Mg}^{2+}$ seawater (Fig. 12) and normal seawater (Fig. 10). First, in $\mathrm{Hi} \mathrm{Ca}^{2+}, \mathrm{Hi} \mathrm{Mg}^{2+}$ seawater there was no second peak at the offset of the tap, suggesting that the second response in normal seawater is attributable to firing of interneurons (perhaps when they are released from inhibition that occurs during the tap) rather than firing of known or unknown sensory neurons. Second, in $\mathrm{Hi} \mathrm{Ca}^{2+}$, $\mathrm{Hi} \mathrm{Mg}^{2+}$ seawater there were no obvious changes in the shape of the PSP during habituation, dishabituation, and sensitization. In particular, the initial peak of the PSP changed as much as the rest of the PSP, whereas in normal seawater the initial peak of the PSP was relatively constant, suggesting that it includes a contribution from nonplastic interneurons.

Depression of the total area of the PSP during habituation was very similar in $\mathrm{Hi} \mathrm{Ca}^{2+}$, $\mathrm{Hi} \mathrm{Mg}^{2+}$ seawater (Fig. 11) and normal seawater (Fig. 9), suggesting that depression of monosynaptic sensory neuron-motor neuron PSPs contributes importantly to habituation of the reflex, in agreement with earlier reports (Castellucci et al., 1970; Byrne et al., 1978b). In $\mathrm{Hi} \mathrm{Ca}^{2+}, \mathrm{Hi} \mathrm{Mg}^{2+}$ seawater there was significant facilitation of the PSP 2.5 min after the shock during dishabituation and sensitization, and less facilitation by $12.5 \mathrm{~min}$ (Fig. 11). This result suggests that facilitation of monosynaptic PSPs contributes importantly to dishabituation and sensitization 2.5 min after the shock, in agreement with results from previous studies (Castellucci et al., 1970; Walters et al., 1983; Wright et al., 1991; Trudeau and Castellucci, 1993). The decline in the PSP from $2.5 \mathrm{~min}$ to $12.5 \mathrm{~min}$ during dishabituation suggests that the process underlying dishabituation (facilitation) is superimposed on the process underlying habituation (depression) and does not remove or reverse it (Groves and Thompson, 1970; Carew et al., 1971). By contrast, in normal seawater there was little facilitation of the PSP 2.5 min after the shock during dishabituation, but significant facilitation $12.5 \mathrm{~min}$ after the shock. Comparison of these results suggests that facilitation of the monosynaptic PSPs is offset partly by inhibition of interneurons $2.5 \mathrm{~min}$ after shock, and that facilitation of interneurons contributes to dishabituation $12.5 \mathrm{~min}$ after the shock.

\section{Mechanisms contributing to habituation, dishabituation, and sensitization}

Figure 13 summarizes some of the conclusions that can be drawn from these results. Habituation in this preparation seems to be attributable largely to depression at sensory neuron synapses; however, dishabituation and sensitization involve several mechanisms at different loci, with different time courses. Two and one half minutes after shock, sensory neuron synapses are strongly facilitated, and enhancement in the periphery (perhaps attributable to PTP at the neuromuscular junction) also makes a substantial contribution. These facilitatory processes, however, are offset partly by transient inhibition of interneurons in the polysynaptic pathway. Twelve and one half minutes after shock, facilitation of sensory neuron synapses and peripheral enhancement are both somewhat reduced, but facilitation in the polysynaptic pathway (attributable in part to disinhibition) makes a contribution, maintaining the behavioral enhancement. Thus, information processing in the neuronal circuit for the reflex is distributed not only in space (Hawkins et al., 1981; Frost et al., 1988; Wright et al., 1991; Trudeau and Castellucci, 1993), but also in time, with different loci and mechanisms of plasticity contributing preferentially at different times.

The model illustrated in Figure 13 also suggests a possible explanation for some of the differences that have been observed between dishabituation and sensitization. Specifically, shock produces transient inhibition of the siphon component of the withdrawal reflex at both the behavioral and cellular levels, but that inhibition is smaller (and net facilitation is larger) during dishabituation than during sensitization (Mackey et al., 1987; Marcus et al., 1988). On the basis of this and other evidence, Marcus et al. (1988) suggested that dishabituation and sensitization have different underlying mechanisms. Transient inhibition is not observed for the gill-withdrawal component of the reflex behaviorally (Hawkins et al., 1990) (Fig. 5A), but is observed for the complex PSP in LDG1 in normal seawater, and that inhibition is smaller (and net facilitation is larger) during dishabituation than during sensitization (Fig. 9). We observed, however, no net inhibition and no difference between dishabituation and sensitization in facilitation of the monosynaptic component of the PSP in $\mathrm{Hi} \mathrm{Ca}^{2+}$, $\mathrm{Hi} \mathrm{Mg}^{2+}$ seawater (Fig. 11). Therefore, transient 
inhibition of the complex PSP 2.5 min after shock seems to be restricted to the polysynaptic component. If the polysynaptic component contributes relatively less to the total PSP after habituation training (because of nonlinearities such as thresholds in the interneurons), then inhibition in the polysynaptic component would have less effect on the PSP during dishabituation than during sensitization. Such a mechanism could account for some of the observed differences between dishabituation and sensitization, without requiring any differences in their underlying mechanisms.

The results of these experiments indicate that even simple forms of learning in this simple system involve a somewhat complex integration of a number of different mechanisms at different loci, with different time courses, that in some cases oppose one another. Thus, the behavioral output cannot be accounted for by any single mechanism or site of plasticity. The model we present in Figure 13, however, is also not a highly distributed neural network (Wu et al., 1994). Rather, according to our model, plasticity of the reflex can be accounted for by several specific mechanisms and loci of plasticity in a defined neural circuit, including a limited number of neurons. More importantly, the experiments described in this paper illustrate that this system can be analyzed at the level of individual neurons, some of which (such as LDG1) make a large contribution to the behavior. Several of the important neurons, including the interneurons and one class of sensory neurons (Frost et al., 1997), have not yet been identified, however. Therefore, additional experiments, as well as computational modeling (Hawkins and Frost, 1995), will be necessary to determine whether this approach can quantitatively account for the behavior.

\section{REFERENCES}

Bailey CH, Chen M (1983) Morphological basis of long-term habituation and sensitization in Aplysia. Science 220:91-93.

Byrne JH, Castellucci VF, Carew TJ, Kandel ER (1978a) Stimulusresponse relations and stability of mechanoreceptor and motor neurons mediating defensive gill-withdrawal reflex in Aplysia. J Neurophysiol 41:402-417.

Byrne JH, Castellucci VF, Kandel ER (1978b) Contribution of individual mechanoreceptor sensory neurons to defensive gill-withdrawal reflex in Aplysia. J Neurophysiol 41:418-431.

Carew TJ, Castellucci VF, Kandel ER (1971) An analysis of dishabituation and sensitization of the gill-withdrawal reflex in Aplysia. Int J Neurosci 2:79-98.

Carew TJ, Pinsker H, Rubinson K, Kandel ER (1974) Physiological and biochemical properties of neuromuscular transmission between identified motoneurons and gill muscle in Aplysia. J Neurophysiol 37:1020-1040.

Castellucci VF, Pinsker H, Kupfermann I, Kandel ER (1970) Neuronal mechanisms of habituation and dishabituation of the gill-withdrawal reflex in Aplysia. Science 167:1745-1748.

Castellucci VF, Carew TJ, Kandel ER (1978) Cellular analysis of longterm habituation of the gill-withdrawal reflex in Aplysia californica. Science 202:1306-1308.

Evarts EV (1973) Motor cortex reflexes associated with learned movements. Science 179:501-503.

Frazier WT, Kandel ER, Kupfermann I, Waziri R, Coggeshall RE (1967) Morphological and functional properties of identified neurons in the abdominal ganglion of Aplysia californica. J Neurophysiol 30:1288-1351.

Frost L, Kaplan SW, Cohen TE, Henzi V, Kandel ER, Hawkins RD (1997) A simplified preparation for relating cellular events to behavior: contribution of LE and unidentified siphon sensory neurons to mediation and habituation of the Aplysia gill- and siphon-withdrawal reflex. J Neurosci 17:2901-2914.

Frost WN, Castellucci VF, Hawkins RD, Kandel ER (1985) Monosynaptic connections made by the sensory neurons of the gill- and siphonwithdrawal reflex in Aplysia participate in the storage of long-term memory for sensitization. Proc Natl Acad Sci USA 82:8266-8269.

Frost WN, Clark GA, Kandel ER (1988) Parallel processing of shortterm memory for sensitization in Aplysia. J Neurobiol 19:297-334.

Groves PM, Thompson RF (1970) Habituation: a dual-process theory. Psychol Rev 77:419-450.
Hammond PH (1954) Involuntary activity in biceps following the sudden application of velocity to the abducted forearm. J Physiol (Lond) 127:23P.

Hawkins RD, Bruner J (1981) Activity of excitor and inhibitor claw motor neurones during habituation and dishabituation of the crayfish defense response. J Exp Biol 91:145-164.

Hawkins RD, Frost L (1995) Contribution of LE siphon sensory neurons to habituation, dishabituation, and sensitization of the gill-withdrawal reflex in Aplysia. Soc Neurosci Abstr 21:1024.

Hawkins RD, Kandel ER (1984) Is there a cell biological alphabet for simple forms of learning? Psychol Rev 91:375-391.

Hawkins RD, Castellucci VF, Kandel ER (1981) Interneurons involved in mediation and modulation of gill-withdrawal reflex in Aplysia. II. Identified neurons produce heterosynaptic facilitation contributing to behavioral sensitization. J Neurophysiol 45:315-326.

Hawkins RD, Abrams TW, Carew TJ, Kandel ER (1983) A cellular mechanism of classical conditioning in Aplysia: activity-dependent amplification of presynaptic facilitation. Science 219:400-405.

Hawkins RD, Cohen TE, Henzi VA, Kandel ER (1990) Parallel dishabituation and sensitization with no inhibition of the gill-withdrawal reflex in Aplysia. Soc Neurosci Abstr 16:19.

Hawkins RD, Cohen TE, Kandel ER (1992) Motor neuron correlates of dishabituation and sensitization of the gill-withdrawal reflex in Aplysia. Soc Neurosci Abstr 18:940.

Hawkins RD, Greene W, Kandel ER (1993) Classical conditioning, differential conditioning, and second-order conditioning of the Aplysia gill-withdrawal reflex in an isolated mantle organ preparation. Soc Neurosci Abstr 19:17.

Jacklet JW, Rine J (1977) Facilitation at neuromuscular junctions: contribution to habituation and dishabituation of the Aplysia gill withdrawal reflex. Proc Natl Acad Sci USA 74:1267-1271.

Kaplan SW, Kandel ER, Hawkins RD (1993) Plasticity in the monosynaptic component of the Aplysia gill-withdrawal reflex during habituation, dishabituation, and sensitization. Soc Neurosci Abstr 19:16.

Kupfermann I, Castellucci VF, Pinsker H, Kandel ER (1970) Neuronal correlates of habituation and dishabituation of the gill-withdrawal reflex in Aplysia. Science 167:1743-1745.

Kupfermann I, Carew TJ, Kandel ER (1974) Local, reflex, and central commands controlling gill and siphon movements in Aplysia. J Neurophysiol 37:996-1019.

Lukowiak K (1977) CNS control of the PNS-mediated gill-withdrawal reflex and its habituation. Can J Physiol Pharmacol 55:1252-1262.

Lukowiak K (1980) CNS control over gill reflex behaviors in Aplysia: satiation causes an increase in the suppressive control in older but not young animals. J Neurobiol 11:591-611.

Lukowiak K, Freedman L (1983) The gill withdrawal reflex in sexually active Aplysia is suppressed. Can J Physiol Pharmacol 61:743-748.

Lukowiak K, Colebrook E (1988) Classical conditioning alters the efficacy of identified gill motor neurons in producing gill withdrawal movements in Aplysia. J Exp Biol 140:273-285.

Mackey SL, Glanzman DL, Small SA, Dyke AM, Kandel ER, Hawkins RD (1987) Tail shock produces inhibition of the siphon-withdrawal reflex of Aplysia: possible behavioral role for presynaptic inhibition mediated by the peptide Phe-Met-Arg-Phe-NH2. Proc Natl Acad Sci USA 84:8730-8734.

Marcus EA, Nolen TG, Rankin CH, Carew TJ (1988) Behavioral dissociation of dishabituation, sensitization, and inhibition in Aplysia. Science 241:210-213.

Trudeau L-E, Castellucci VF (1992) Contribution of polysynaptic pathways in the mediation and plasticity of the Aplysia gill and siphon withdrawal reflex: evidence for differential modulation. J Neurosci 12:3838-3848.

Trudeau LE, Castellucci VF (1993) Sensitization of the gill and siphon withdrawal reflex of Aplysia: multiple sites of change in the neuronal network. J Neurophysiol 70:1210-1220.

Walters ET, Byrne JH, Carew TJ, Kandel ER (1983) Mechanoafferent neurons innervating tail of Aplysia. II. Modulation by sensitizing stimuli. J Neurophysiol 50:1543-1559.

Wright WG, Marcus EA, Carew TJ (1991) A cellular analysis of inhibition in the siphon withdrawal reflex of Aplysia. J Neurosci 11:2498-2509.

Wu J-Y, Cohen LB, Falk CX (1994) Neuronal activity during different behaviors in Aplysia: a distributed organization. Science 263:820-823. 